\title{
Prospects for national agriculture in the new reality
}

\author{
Madina Eneeva $^{1}$, Madina Gazaeva ${ }^{1}$, Takhir Toguzaev ${ }^{1}$, Magamed Israilov $^{1}$, and \\ Zalim Kaisinov ${ }^{2}$ \\ ${ }^{1}$ Kabardino-Balkarian State Agricultural University named after V.M. Kokov, Lenin Avenue, 1V, \\ 360030 Nalchik, Russia \\ ${ }^{2}$ Regional Fund "Center for Entrepreneurship Support of the KBR"
}

\begin{abstract}
The term "new reality" entered the lexicon of economists in the last decade. It means fundamental changes in the economy, which are predominantly economic in nature, also expanded in engineering and technology, sociology, politics and psychology. In 2020, the "new reality" supplemented with Covid-19. It seems that the reason for its strong influence on the economy is that Covid-19 is becoming a kind of economic factor related not even with the development of pharmacology, epidemiology, etc., but with the fact that it touched one of the most dynamically developing spheres of the economy - services. Agriculture has also faced the "new reality" in a new century. But in contrast to the economy, its "new reality" is formed by qualitatively different factors: climate, weather, social polarization of societies, increased consumption and decrease of the matrix of basic factors of agricultural production. In this regard, a study of the prospects for national agriculture merits attention.
\end{abstract}

\section{Introduction}

Modern achievements in agriculture are as follows: precision farming, growing vegetables, mushrooms and berries on the principles of hydroponics, intensive horticulture, robotic dairy farms, as well as cattle feeding complexes, poultry farms, pig farms, etc., actually represent a new wave (a kind of re-) industrialization [1]. These are all industrial technologies. Consequently, we seem to return to the 30s of the last century. Obviously, the above pattern will give a certain growth, however, firstly, it will not be so high, secondly, it will not be so long, and thirdly, it does not exclude new crises, etc., but above all, fourthly, it shows limited efficiency (high total costs with low results). For example, intensive orchards (and horticulture in general), as well as vegetable growing together with similar technologies in animal husbandry, have their own limited (time) period, so-called life cycle (LC). Moreover, according to some analysts, "this miracle of bioengineering cannot live on its own", since it requires active mineral feeding, chemical protection and huge water consumption. The situation in beef cattle production is as follows: poultry production ranks first in terms of profitability (currently existing technologies allow to fatten a broiler in 42 days, to increase the egg-laying capacity and also change the poultry appearance (to decrease density and size of feather, etc.), as well as pigs (pig is brought to the required 
commercial condition in 6 months). The longest growing process is retained by cattle (it takes 18 months to bring the bull to a lean condition). Under the most favorable conditions, no further than the mid-30s and early 40s. Then comes their natural extinction (this should be kept in mind when investing). Using and investing in such technologies we limit ourselves in the trajectory of development, i.e. we plan our backlog in advance. And that's what matters.

\section{Materials and Methods}

The theoretical and methodological basis of the study is worked out and represents a theory of systems. At the same time, there are some peculiarities related to food and agricultural products.

\subsection{Methods}

The study is based on a set of analytical and descriptive methods to identify, formalize and quantify current economic, organizational, technological and institutional ties between various sectors and AIC segment. Among the analytical methods, the emphasis is on the correlation-regression and index methods to quantify the relationship, identify proportions between different sectors and segments. Among descriptive methods, attention is paid to the description of obtained dependencies, identified trends and proportions. The main purpose is to interpret the obtained estimations.

The empirical study is based on the official statistics, systematized in the statistical collections of the FSSS of Russia (Rosstat), its territorial branch for the KBR (TB FSSS Kabardino-Balkariyastat). In addition to the mentioned Rosstat data, the results of works of foreign and domestic researchers are used as an empirical base.

\section{Results and Discussion}

The majority of experts currently accept that the main problem of the development of agriculture in the country is associated with several factors: firstly, seed material (currently imported seed material is used for most agricultural crops; the domestic material share is generally not more than $10 \%$; moreover, it is poorly adapted to soil local conditions, agricultural landscape, etc.), secondly, technologies (most technologies are resource and energy intensive; the resource and energy consumption per unit of the produced product of domestic agriculture exceeds foreign ones by several times. Besides, the main technologies are either completely foreign or on foreign licenses and patents), thirdly, ecology (the use of intensive technologies has a great impact on soil, water and the surrounding system as a whole. They are frequently used without regard to environmental impact and environmental assessment. Especially negative effects cause the use in areas with ..., which include the territories of the far north, tundra, mountains, waterways), fourthly, the low processing level of the produced product. Similar problems are observed in animal breeding. Primarily, low development of the meat market and meat and dairy industry in Russia as a whole results in high production cost of both beef meat and milk [2]. Experts believe that the reason for the high prime cost of beef and milk is "in the economic inefficiency of the projects chosen by our businessmen". According to experts, the main idea of "cheap meat" is the cooperative model, in which "small family farms integrate and cooperate with larger partners" using a system of labor division. Small family farms raise newborn calves up to 8-12 months. And then the larger partners purchase young bulls with further fattening and slaughter. In the USA, 7,000 thousand farmers maintain 15 million livestock animals. 
Meanwhile in Russia, the main meat livestock is concentrated in agricultural holdings, where the cost of calf management is 1.5-2 times higher due to additional costs of managing a huge farm". For this reason, the National Union of Beef Producers (NUBP) promotes the idea of integrating farmers and larger businesses. "This model should be based on families, each contains 150-200 heads. A promising farming business begins with this amount, although both small farmers and private household plots can participate in such cooperation." They believe that by integrating farmers with larger companies, beef farming will grow faster. In our view, the problem (and reason) of the low development of domestic livestock and dairy production has been identified. But we believe that the proposed solution is incorrect, i.e. leading to a dead end. Basically, an evolutionary path of development and problem solution is proposed. But first, let us provide a few comments on this proposal.

At the outset, in our view, it is irrelevant to compare the North American model of organization and management of cattle breeding with the Russian one. Dating back to the pre-Soviet times, the Russian model assumed both landlord farms and farmsteads, and if the former grew into collective (collective-farm), state-owned farms, then the second grew into personal subsidiary farms (private farms or modern peasant farms). This is a historical practice. It seems impossible to change it while remaining within the traditional farming model. Industrialization just only corrected this model, but did not change it due to the significant conditions in Russia: large territories, lack of private ownership of land, etc. But it seems to be a purely technical or even ideological incorrectness, which could be ignored as meaningless, as domestic practice since the $90 \mathrm{~s}$ and even the end of the $80 \mathrm{~s}$ has shown that the farmer's way of developing national agriculture for Russia is both dead-end and impossible. And it is not only about psychology, but also about practice. As a matter of fact, in the same source it is reported that "half of the cattle are still in personal subsidiary plots (PSP). Nevertheless, there are less people willing to keep their own livestock. And the increase in beef production by farmers and at agricultural enterprises (for ten years the share of herd of peasant farm enterprises and agricultural firms increased by only $10 \%$ ) does not compensate the decrease in the output of private household plots. A more significant mistake, in our view, is the proposal to form cooperative and integration ties in the organization of the cattle-breeding segment of the national agriculture. Such model has a so-called attractive character, but actually it causes (and will produce) a slowdown associated with a shortage of investment. This situation is caused by the current economic growth in agriculture, which is associated with industrialization, i.e. has a structural character. The very model of such growth (and development) was first described by J. Schumpeter [3] back in the last century, it is kept on constant investment and innovation, which are of a limiting nature. The point is that increasing investment is required to ensure continued growth; wherein, the growth rate of the investments should not be lower, and the further from the beginning, the higher than the economic growth itself. This paradox of industrial or structural growth is reflected in the PRC, as well as other countries, including our own history $[4,5,6,7]$. There is one more aspect in this attractive project, which can be illustrated, for example, by the agriculture in Kabardino-Balkaria, one of the most advanced and developed in Russia. The point is that most of the investments are directed to limited sectors and segments that are very attractive (i.e., they give the maximum return since the absence of the competitors in such niche, i.e., there is an absolute advantage). For example, in the KBR there is a crop production, and within it there is a segment related to: a) horticulture (intensive horticulture is the main consumer of investments inside this segment, its share in the total investment in agriculture is bigger than the half); b) vegetable growing (within which, also there is a dominant segment - growing tomatoes in greenhouses); c) viticulture, (with a high share of investments). The fourth sector is animal husbandry, within which the dominant positions are taken by: poultry and cattle breeding (cattle). 
Other sectors and segments of the agro-food market: fish farming, berry farming, beekeeping, as well as sheep breeding, goat breeding, horse breeding, etc., occupy a rather small share in the investment system. Due to the listed sectors and investments in them, the agriculture of the KBR is among the leading in the technological and technical equipment of industries in Russia [8,9]. Particularly, we proceed from the existing criteria, for example, the volume of grain production per capita exceeds $1000 \mathrm{~kg}$, the republic has achieved a kind of food security, has a high level of provision of the population with vegetables, fruits, as well as meat, etc. The share of the products of these agricultural sectors in the food export of the KBR is large [10]. However these agricultural sectors (and even segments) continue to receive an active flow of investments, direct and indirect, due to various kinds of preferences. At the same time, experts do not notice a decrease in return per investment unit. According to the laws of economics, it should be expected, on the one side, an outflow of investments, and on the other, a change in the system of preferences [11]. And if the first is stimulated by the appearance of new sectors and the overflow of capital into them, then the second is stimulated by the first and by the compression of the total volume of investments [12]. Meanwhile to maintain this sector in the existing parameters: employment, share in GRP, share in different levels of incomes to budgets of different levels, etc., it will be necessary to increase the volume of investments in it. In this context, the most important criteria to predict the situation in this sector of agriculture is the assessment of the life cycle (LC) of the created sector and the industries concentrated in it. According to approximate estimates (since exact estimates related to foreign analogs differ, and there are no such data about domestic production), the length of the life cycle of the industrial technologies is 10-15 years. But this period is not final. Due to the acceleration of time in the conditions of new scientific, technical and industrial revolutions it seems to be reduced. There is a reason to reduce this period to $8-12$ years. So what that mean?

Primarily, the current "advanced" technologies in the field of domestic agriculture, described above in a maximum of 15 years, will no longer be associated as such not only in the world, since world agriculture has already reorganized to new technologies in accordance with the criteria of the new industrial, scientific and technological revolution, but even inside the country, since the new technologies are being formed, for example, in the Moscow region, Kuban and a number of other regions of the country. Conversely, this means that already in the middle of the past decade we should have redistributed investment resources from these sectors and these industries to new ones related to the new industrial revolution and the new scientific and technological revolution. But contrary to the logic of development, we continued to carry out massive investments in ... past technologies. It appears, that currently the investments are holding our development stronger than the chains with which Prometheus was chained to the rock. Now our agriculture have to live according to another laws - the laws of dwindling investments, i.e. we are obliged to support the existing production and agricultural sectors until the investments will be exhausted. There is no other way, since we are obliged to pay for investments, i.e. pay interest on loans, support all production, technological, technical, etc. infrastructure (i.e. refrigerators, sorting rooms, the production of posts, nets to containers and caretaker specialists, etc.). Thus, we are in the position of a vicious circle due to the fact that we were involved in the restoration of the industrial matrix, which once (back in the 30s) was successfully carried out, but cannot break out of this industrial paradigm of development. And until we stay within its borders, we will multiply our backlog.

It raises several questions. The first is what to do? The second is where to develop, what is the prospect to strive, which should be formed today? The answer to the first question is to accelerate the search for new mechanisms and models for the transition to innovative agriculture. This task is not easy. The fact is that currently in our agriculture there are at least three different types of agriculture, set into economic structures: a lot of atomized 
peasant households (so-called personal subsidiary plots), peasant farm enterprises and an advanced associated industrial, which concentrated in large agricultural enterprises (VIS and agricultural holdings). Depending on the region, the share of each structure in territorial agriculture is different. Moreover, in different sectors and segments of the agro-food market, this share is also different. Large enterprises ignore not only small regions, but also many sectors and segments. And it's understandable. Their activities are based on obtaining income, profits - super income and super profits, most small regions cannot allow them to expand and to receive their super profits. But even large enterprises are reluctant to innovate and switch to new technologies until their investments have been recouped. As a result, agriculture is held hostage to these principles.

There are two main directions for solving this problem. The first is radical and revolutionary. It is related to the "unfastening" of the existing ballast, which is represented by the first two structures. But the third structure is not advanced, too. It only represents an expanded and industrialized form of the previous ones. Besides, it cannot exist without the two previous structures, since there are sectors and segments of the agro-food market that have no interest for him. The second direction is evolutionary. It is based on cooperation and integration of the first two structures into the third. This is the usual path of development of agriculture, with several subdirections, which were tested in the USSR in the $30 \mathrm{~s}$ and then in the 50s, when industry and advanced agricultural mode (state farms and agro-industrial associations) transferred their experience to collective farms, agricultural cooperatives. Another subdirection is associated with the organizational, financial and technological integration of small peasant farms (households, still mistakenly called personal household plots) to large enterprises (VIS, holdings, etc.). The last direction presupposes a sort of satellite character of relations, formed on the basis of the transfer of some functions to small farms; thus, a kind of belt of small enterprises is forming around large enterprises, which are engaged in the completion and processing of particular industries. In this regard enterprises have not so much an economic function as a social one. This form of relations presupposes that someday small farms (especially peasant farmsteads) will die out, but as long as they exist, it is necessary to provide them with the possibility of existence or residence. Consequently, we are talking about clearing the territory for themselves, which we can currently see. But this, in our view, does not solve the problem.

Agriculture remains the kind of agriculture it was a thousand years ago. So, in this way, we do not solve the global problem - food production without traditional agricultural technologies. And this is the fundamental task set by the current industrial, scientific and technological revolutions. The answer to the second question lies in the major format of the rejection of the so-called traditional agriculture, in which the basic element is the land and the so-called natural environment or the conditions for the transition to precision fermentation technology. There are two mechanisms according to this direction. The first is related to precision technologies that express the accuracy of the problem, i.e. it is needed to know in advance what we want to receive at the exit. Another (second) mechanism is related to fermentation, which means the technological processing of raw materials with the help of special substances to the finished product. As a fermentation system, bioreactors are used, which are a complex of biomaterials/substances (from molecules and ferments to ...) [13]. In general, precision fermentation technology means the creation of food products with the pre-planned properties (taste, food, etc.) in bioreactors. It means that for food production there is no need for land and so-called natural conditions: solar radiation, temperature, humidity, irrigation, land and other known conditions involved in the production of agricultural products. All these processes for the production of the final product take place in a bioreactor - closed autoclaves that can be placed ... in the kitchens of citizens. However, this technology needs several elements: 1) bioreactors, i.e. a set of 
biologically active substances (bacteria) with specific properties, 2) raw materials from which the final products will be produced by bacteria (for example, presscake, etc.), 3) energy to feed the bioreactor.

In this regard, today it is necessary to reform the matrix of agricultural development from industrialization to a new organization, which will be based on precision fermentation.

\section{Conclusions}

Analysis of the state of agriculture leads to the following conclusions: 1) the reindustrialization of national agriculture, which began in the last decade, will lead in the growth of agriculture. However, this growth will turn out to be nondurable and unstable, depending on the conjuncture, and above all, fading and expensive. Increasing costs will be required to provide growth. Eventually, growth will be absorbed by rising costs. Production will reach absolute inefficiency; 2) changes in climate and weather will have the growing negative impact on agriculture. There is a reason to meet the transformation of the economy from taking to protecting, i.e. instead of removing resources from the environment, to spend more on preserving and restoring the natural environment. As a result, we will get an inverted economy. What is needed with respect to the described tendencies: 1) To differentiate national agriculture into several modes (segments): a) weather-dependent (a segment that has a strong dependence on the state of climate and weather and with increasing climate and weather changes will demonstrate a deterioration in its performance. This segment currently occupies the largest volume both in terms of concentration of resources and in terms of production. However, there will be an increase in costs not for the production of products, but for the elimination of the negative impact of climate and weather. Moreover, these costs will grow exponentially and at some point it will become unprofitable to engage in the production of products, because the result will be several times lower than costs. Such circumstances occasionally occurs in the history of agriculture. Recently, it has covered the so-called water-intensive products and their production $[14,15,16]$. In addition, it is necessary to provide a clear zoning of agriculture. Another direction is the use of crops and technologies adapted to changing climatic and weather conditions), b) organic or ecological (a special segment engaged in the production of environmentally friendly products. Its capabilities will remain within the existing capabilities. At the same time, the market capacity of these products is expanding and will continue to grow due to the growth of incomes of the population, on the one side, and the reduction in the production of environmentally friendly products), c) precision (a segment that is related to the development of precision fermentation. This is the least developed and essentially new segment of the current national agriculture. Therefore, an accelerated formation of this sector (segment) of national agriculture is required. But this isn't about traditional precision agriculture based on the use of modern technologies for planning traditional agriculture [17, 18, 19], but of the creation of a new sector of national agriculture, designed to produce food (and agricultural) products directly, bypassing the stage of traditional agriculture), d) (segment associated with the production of bacteriophages. This isn't about the creation of traditional agricultural products and raw materials for food, etc., but the production of bacteria for various industries: from food to pharmaceuticals, hygiene, etc.), e) (a segment associated with the production of intellectual products that do not have material carriers, i.e. formulas, programs, and other products); 2) to ensure continuity and interconnection between segments, similarly to communicating vessels, due to the reciprocal mechanism of overcoming the transfer of agriculture [20]. 


\section{References}

1. V. A. Kushkhova, M. Sh. Gazaeva, A. V. Gyatov, Z. M. Ivanova and M. N. Eneeva, IOP Conference Series: Earth and Environmental Science (2019)

2. A. Kholodov, M. A. Kholodova, I. F. Gorlov, O. P. Shakhbazova, N. I. Mosolov, A. V. Glushenko and D. A. Mosolova, IOP Conference Series: Earth and Environmental Science (2019)

3. J. Schumpeter, The Theory of Economic Development (1982)

4. I. V. Stalin, Economic Problems of Socialism in the USSR (1952)

5. R. K. Allen, Capital Accumulation, Soft Budget Constraints and Soviet Industrialization (1997)

6. R. Allen, From Farm to Factory: A New Interpretation of the Soviet Industrial Revolution (2013)

7. G. I. Khanin, Free Thought-XXI, 5, 72-94 (2002)

8. H. M. Rakhaev et al., Agriculture of Kabardino-Balkaria: state, potential, problems, prospects for modernization (2016)

9. V. A. Kushkhova, E. S. Bakkuev, Z. M. Ivanova, A. M. Tramova and Z. M. Khochueva, IOP Conference Series: Earth and Environmental Science, 42007 (2019)

10. A. V. Gyatov, S. A. Bogatskaya, M. H. Zhetteeva, Agrarian Bulletin of the Urals, 4, 91-100 (2020).

11. N. G. Baryshnikov, E. A. Cherdantseva, Reproduction in Agriculture: Priorities and Prospects (2012)

12. K. Marx, Capital: The Process of Capitalist Production, 2 (1978)

13. Yu. A. Ramazanov, Biotechnology: State and Development Prospects, 287-289 (2015)

14. Global Climate Change and Risk Forecast in Agriculture in Russia (2009)

15. V. P. Yakushev, E. E. Zhukovsky, Bulletin of RAAS, 2 (2010)

16. H. M. Rakhaev, A. V. Gyatov, Agrarian Bulletin of the Urals, 12(179), 27-32 (2018)

17. T. M. Batte, W. M. Arnholt, Computers and Electronics in Agriculture, 38, 125-139 (2003)

18. Precision Agriculture (2009);

19. Machine Technologies for the Production of Products in the System of Precision Farming and Animal Husbandry: Materials of the 3rd Scientific and Practical Conference (2005)

20. F. M. Tallas, M. R. Uyanaev, Economics and Entrepreneurship, 4-2, 1085-1088 (2015) 